\title{
Opportunistic screening for COPD in primary care: a pooled analysis of 6,710 symptomatic smokers and ex-smokers
}

This article was published in the following Dove Press journal: International Journal of Chronic Obstructive Pulmonary Disease

\author{
Andreas Katsimigas' \\ Oliver Djurhuus Tupper' \\ Charlotte Suppli Ulrik ${ }^{1,2}$ \\ 'Respiratory Research Unit, Department \\ of Respiratory Medicine, Hvidovre \\ Hospital, Hvidovre, Denmark; ${ }^{2}$ Institute \\ of Clinical Medicine, Faculty of Health \\ Sciences, University of Copenhagen, \\ Copenhagen, Denmark
}

Objective: To investigate the prevalence and predictors of COPD in a large cohort of symptomatic smokers and ex-smokers in a primary care setting.

Methods: General practitioners $(n=390)$ consecutively recruited individuals $\geq 35$ years, with current or previous tobacco exposure, at least one respiratory symptom, and no previous diagnosis of obstructive airways disease; and obtained data on tobacco exposure, body mass index (BMI), and dyspnea (Medical Research Council dyspnea scale). All individuals with airflow obstruction, ie, $\mathrm{FEV}_{1} / \mathrm{FVC}<0.70$ at initial lung function test, had diagnostic spirometry, including bronchodilator reversibility test. COPD was defined as respiratory symptom(s), tobacco exposure, and nonreversible airflow limitation.

Results: Of the 6,710 at-risk individuals screened with spirometry ( $52 \%$ male sex, mean age 58 years [SD 10.9]), 1,185 were diagnosed with COPD (17.7\%). Apart from age and packyears, multivariate logistics regression analysis, adjusted for $\mathrm{FEV}_{1}$, revealed that $\mathrm{BMI}<25$ $\mathrm{kg} / \mathrm{m}^{2}$ (OR 4.2, 95\% CI 3.0-5.9, $p<0.001$ ), BMI 35+ kg/m² (OR 1.6, 95\% CI 1.2-2.3), selfreported dyspnea (OR 1.2, 95\% CI 1.1-14, $p=0.04$ ), wheeze (OR 1.3, 95\% CI 1.1-1.6, $p=0.001$ ), phlegm (OR 1.4, 95\% CI 1.1-1.6, $p<0.001$ ), and MRC $\geq 3$ (OR 1.6, 95\% CI 1.2 $2.0, p=0.001)$ were associated with a significantly higher likelihood of being diagnosed with COPD. No association was found between sex, cough, and recurrent respiratory tract infections and a diagnosis of COPD.

Conclusion: The prevalence of COPD is high among smokers and ex-smokers with one or more respiratory symptoms seen in primary care, and the presence of wheeze, phlegm and dyspnea, together with both low BMI and obesity identify a subgroup with an even higher likelihood of COPD.

Keywords: early COPD, general practice, screening, lung function tests, reversibility

\section{Introduction}

COPD has a significant impact on life expectancy worldwide, illustrated by a close to $10 \%$ increase in mortality from 2000 to $2015 .^{1}$ Despite increasing public awareness and more advanced treatment options, according to estimates made by the European Respiratory Society, the proportion of deaths caused by COPD will continue to increase both worldwide and in Europe until at least $2030 .^{2}$

COPD is often diagnosed late in the course of the disease. ${ }^{3}$ A way to counteract this may be secondary prevention by early diagnosis and intervention, as smoking cessation is an effective way to slow the decline in lung function as well as the progression of respiratory symptoms. ${ }^{4,5}$ One way to achieve this goal may be
Correspondence: Charlotte Suppli Ulrik Respiratory Research Unit, Department of Respiratory Medicine, Hvidovre Hospital, Hvidovre DK-2650, Denmark Email csulrik@dadlnet.dk 


\section{Box I}

Grade

I. "I only get breathless with strenuous exercise"

2. "I get short of breath when hurrying on the level or up a slight hill"

3. "I walk slower than people of the same age on the level because of breathlessness or have to stop for breath when walking at my own pace on the level"

4. "I stop for breath after walking 100 yards or after a few minutes on the level'

5. "I am too breathless to leave the house"

Notes: 100 yards $=91 \mathrm{~m}$. Reproduced from: Medical Research Council. Medical Research Council Dyspnoea scale. Available from: https://mrc.ukri.org/research/facilities-and-resources-for-researchers/mrc-scales/mrc-dyspnoea-scale-mrc-breathlessness-scale/. Used with the permission of the Medical Research Council. ${ }^{12}$

systematic screening for COPD in general practice, as previous studies have revealed a high prevalence of undiagnosed COPD among individuals at high risk due to symptoms and tobacco exposure. ${ }^{3,6}$ Furthermore, in many countries, the general practitioners (GPs) serve as gatekeepers for referral to secondary care management. It is therefore of utmost importance that GPs have not only awareness but also tools to identify individuals at risk requiring further diagnostic workup.

The present study was based on a pooled analysis of data from two studies of opportunistic screening for COPD in primary care. The primary aim was to investigate the prevalence of undiagnosed COPD among symptomatic smokers and ex-smokers. The secondary aim was to identify predictors of COPD in this high-risk group.

\section{Materials and methods}

\section{Study design}

This is a pooled analysis of data obtained from two similar studies of screening at-risk individuals for COPD in primary care. ${ }^{7,8}$ Each of the studies aimed to include $5 \%$ of the Danish GPs, ie, approximately 200 GPs for each of the studies from all over Denmark. This strategy allows a representative sample of the Danish population. The GPs were asked to recruit and examine at least 20 subjects from their own practice who met all the inclusion criteria and none of the exclusion criteria. All procedures were performed by the GP in his/her practice. In the study by Kjeldgaard et al, the GPs were trained in the use of COPD-6 screening device, but for all other measurements in the studies, the participating GPs used their own equipment. $^{7}$

\section{Study population}

All eligible individuals fulfilled the following criteria: 1) age $\geq 35$ years, 2) current smoker or ex-smoker, 3) at least one of the following respiratory symptoms: dyspnea, cough, wheeze, sputum and recurrent lower respiratory tract infections, and none of the exclusion criteria: 1) inability to perform spirometry or 2) being previously diagnosed with an obstructive lung disease, ie, asthma or COPD.

All subjects had spirometry performed with at least three forced expiratory maneuvers and at least two of those differing $<5 \%$ for highest obtained measurement of both $\mathrm{FEV}_{1}$ and FVC. Spirometry was performed according to spirometry guidelines from the Danish Respiratory Society. ${ }^{9}$ In the study by Kjeldgaard et al, participants were screened using the COPD- 6 device before proceeding, if indicated, to confirmatory spirometry. ${ }^{7}$

Data on age, sex, height, body weight, smoking status, number of years smoked, daily tobacco consumption, current respiratory symptoms and severity of dyspnea according to the Medical Research Council (MRC) Dyspnoea scale $^{10}$ (Table 1) were collected and entered into a consolidated web database. $\mathrm{FEV}_{1} \%$ predicted (European Community of Steel and Coal reference values were used for both studies), FVC, $\mathrm{FEV}_{1} / \mathrm{FVC}$ ratio, pack-years and body mass index (BMI) were automatically calculated based on the obtained data. ${ }^{7,8,11}$

Table I Basic characteristics of the screened subjects $(n=6,7 \mid 0)$ divided according to COPD status

\begin{tabular}{|l|l|l|l|}
\hline & $\begin{array}{l}\text { No COPD } \\
(\mathbf{n}=5,525)\end{array}$ & $\begin{array}{l}\text { COPD } \\
(\mathbf{n}=1,185)\end{array}$ & $p$-value \\
\hline $\begin{array}{c}\text { Sex } \\
\text { Males }\end{array}$ & $51.5 \%$ & $53.8 \%$ & NS \\
\hline Age (years) & $57.0(11.7)$ & $63.3(10.6)$ & $<0.001$ \\
\hline $\begin{array}{l}\text { BMI (kg/ } \\
\left.\mathrm{m}^{2}\right)\end{array}$ & $27.3(5.0)$ & $24.8(5.0)$ & $<0.001$ \\
\hline $\begin{array}{c}\text { Smoking } \\
\text { CS }\end{array}$ & $41.3 \%$ & $34.7 \%$ & $<0.001$ \\
\hline Pack-years & $29.4(20.9)$ & $38.8(22.5)$ & $<0.001$ \\
\hline FEV 1 (L) & $2.8(0.8)$ & $1.9(0.7)$ & - \\
\hline FEV 1 /FVC & $0.8(0.1)$ & $0.6(0.1)$ & - \\
\hline FEV $\%$ pred & $92.0(17.0)$ & $66.9(18.3)$ & - \\
\hline
\end{tabular}

Notes: Data shown as mean (SD).

Abbreviations: BMI, body mass index; CS, current smoker; NS, nonsignificant. 


\section{Diagnostic algorithm}

Participants with airway obstruction $\left(\mathrm{FEV}_{1} / \mathrm{FVC}<0.70\right)$ at the initial spirometry had a bronchodilator reversibility test performed with $0.4 \mathrm{mg}$ of inhaled salbutamol (or equivalent) followed by repeated spirometry 15 mins later. Based on the increase in $\mathrm{FEV}_{1}$, participants with an increase of $\geq 500 \mathrm{~mL}$ were classified as having asthma and excluded from further analyses. For a more detailed description of the methods see the papers by Lokke et al and Kjeldgaard et al.,

COPD was defined as respiratory symptoms, tobacco exposure and nonreversible airflow limitation, ie, postbronchodilator $\mathrm{FEV}_{1} / \mathrm{FVC}$ ratio $<0.70 .^{13}$

\section{Statistics}

Statistical analyses were performed with the software SPSS v. 27.0 (IBM). The analyses were limited to participants with complete data. Data were tested for normality, and nonparametric tests were used to analyze continuous data. Categorical data were analyzed by the MannWhitney U-test. In all statistical analyses, a two-tailed $p$-value of $\leq 0.05$ was considered significant. Multivariate logistic regression analysis was used to evaluate predictors for a diagnosis of COPD and reported as odds ratios with $95 \%$ confidence intervals and $p$-values. In the latter analyses, participants were stratified according to BMI into three groups, ie, BMI $<25 \mathrm{~kg} / \mathrm{m}^{2}$, BMI $>35 \mathrm{~kg} / \mathrm{m}^{2}$ and the remaining participants as the reference group.

\section{Ethics}

Both studies were endorsed by the Danish College of General Practitioners. According to the European Federation of Pharmaceutical Industries and Associations code and the Danish Association of the Pharmaceutical Industry, both studies were nondrug, noninterventional studies. Approval from the Danish Scientific Ethics Committee and the Danish Medicines Agency were, therefore, not mandatory for the two studies, but they were given all relevant study information. Data handling was approved for both studies by the Danish Data Protection Agency.

\section{Results}

\section{Study cohort}

A total of 390 GPs (approximately 11\% of all Danish GPs) from all parts of Denmark participated in the two studies and recruited a total of 6,710 symptomatic individuals (52\% male sex, mean age 58 years [SD 10.9]), 60\% current smokers, mean number of pack-years 33 (SD 21.5) at risk of COPD.

\section{Prevalence of respiratory symptoms and COPD}

The most common respiratory symptom was a cough, with a presence in almost $3 / 4$ of individuals in both COPD and non-COPD participants (Figure 1).

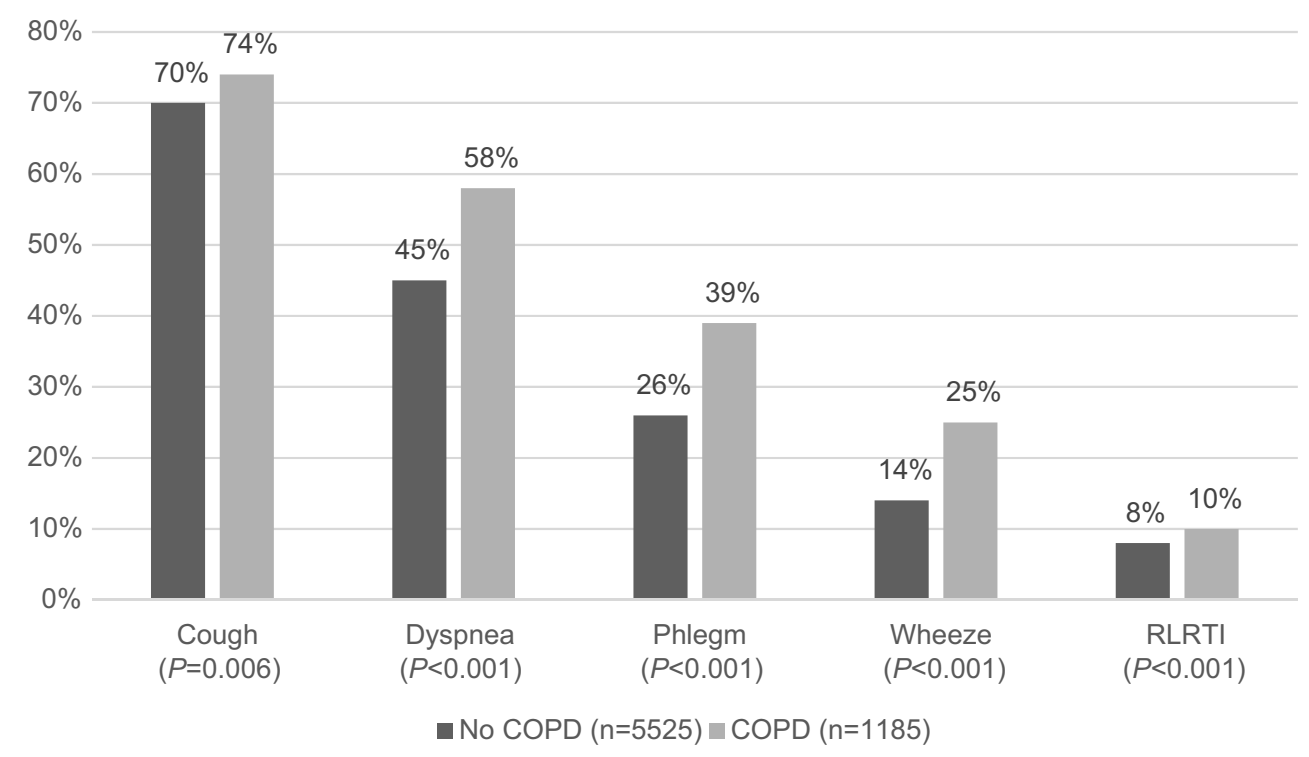

Figure I Prevalence of respiratory symptoms, ie, cough, dyspnea, phlegm, wheeze and recurrent lower respiratory tract infections (RLRTI) in participants with and without COPD, respectively. 
A total of 1,185 participants (17.7\%) fulfilled the diagnostic criteria for COPD, ie, respiratory symptoms, tobacco exposure and nonreversible airflow limitation.

\section{Comparison of participants with and without COPD}

On average, the participants with COPD were older, had lower BMI and had more pack-years of smoking (Table 1).

\section{Predictors of COPD}

Among the basic characteristics, BMI was shown to be the strongest predictor for subjects diagnosed with COPD. This was true for subjects with BMI $<25 \mathrm{~kg} / \mathrm{m}^{2}$ and subjects with BMI $>35 \mathrm{~kg} / \mathrm{m}^{2}$. Both were in reference to subjects with a BMI between 25 and $35 \mathrm{~kg} / \mathrm{m}^{2}$. Among symptoms sputum, wheeze and dyspnea were found to be significant predictors of COPD. The severity of dyspnea was found to be a significant predictor of COPD as well, measured as an MRC score of $\geq 3$. These results are given in Table 2.

\section{Discussion}

This was a large pooled analysis of two studies of opportunistic screening for COPD in a primary care setting. We found that among smokers and ex-smokers, and by that at

Table 2 Risk factors associated with new diagnosis of COPD among 6,710 symptomatic smokers and ex-smokers identified in general practice

\begin{tabular}{|l|l|l|l|}
\hline Risk factor & OR & 95\% CI & -value \\
\hline Pack-years $(/ / 0)$ & 1.06 & $1.03-1.09$ & $<0.001$ \\
\hline Symptoms & & & \\
Dyspnea & 1.2 & $1.0-1.4$ & 0.039 \\
Phlegm & 1.3 & $1.1-1.6$ & $<0.001$ \\
Wheeze & 1.3 & $1.1-1.6$ & 0.012 \\
\hline MRC score 3+ & 1.6 & $1.2-2.0$ & 0.001 \\
\hline Age & & & \\
$40-49$ years & 1.6 & $0.9-1.8$ & 0.120 \\
$50-59$ years & 2.4 & $1.4-4.1$ & 0.002 \\
$60-69$ years & 3.5 & $2.0-6.0$ & $<0.001$ \\
$\geq 70$ years & 3.9 & $2.2-6.7$ & $<0.001$ \\
\hline BMI group & & & \\
$<25\left(\mathrm{~kg} / \mathrm{m}^{2}\right)$ & 4.2 & $3.0-5.9$ & $<0.001$ \\
$>35\left(\mathrm{~kg} / \mathrm{m}^{2}\right)$ & 1.6 & $1.1-2.2$ & 0.006 \\
\hline
\end{tabular}

Note: MRC score 3+: an MRC score of 3-5 compared to an MRC score of I-2. Abbreviations: MRC, Medical Research Council dyspnea scale; BMI, body mass index. risk for COPD, that individuals with wheeze, phlegm, dyspnea, and a low BMI or high BMI were significantly more likely to be diagnosed with COPD.

Prevalence of COPD was found to be $17.7 \%$. Other studies such as Hansen et al and Miravitlles et al have found a lower prevalence of COPD of $12 \%$ and $10 \%$, respectively. ${ }^{14,15}$ The lower prevalence reported in the previously mentioned studies might be explained by them including never-smokers. Never-smokers as a group have a significantly lower risk of being diagnosed with COPD thereby bringing down the prevalence of the cohort. The study by Minas et al found a prevalence of COPD of $18.4 \%$ though almost half of the subjects in the cohort were never-smokers. ${ }^{16}$ This, however, can be explained by them including subjects who were previously diagnosed with COPD in their analysis. If they had excluded these subjects the study by Minas et al would have reached a prevalence of $13 \%$ which is comparable to the previously mentioned studies that included neversmokers. ${ }^{14,15,16}$ Studies that include only ever smokers found a similar prevalence of undiagnosed COPD as in our study. Llordes et $\mathrm{al}^{17}$ found a prevalence of $15.5 \%$ of undiagnosed COPD cases among ever smokers, after excluding individuals with a previous COPD diagnosis. Jordan et $\mathrm{al}^{18}$ found a massive prevalence of $32 \%$ $(\mathrm{n}=662)$ of undiagnosed cases of COPD among individuals who had respiratory symptoms (chronic cough, phlegm, wheeze and exertional breathlessness) and attended spirometry. A large amount of study participants (36.7\%, $\mathrm{n}=1,199$ ) who had positive respiratory symptoms did not attend diagnostic spirometry, and this could potentially explain the relatively higher prevalence found vs that found in our study.

In concordance with the present study, other studies have found the presence of wheeze, phlegm and dyspnea to be independent predictors of COPD. ${ }^{16,19}$ In addition to any degree of dyspnea being a significant predictor, it was shown that the severity of dyspnea based on MRC score was significant as well. This correlates well with our clinical understanding of COPD and is backed up by the literature. $^{20,21}$

Age was shown to be a reliable predictor of COPD, with significant increases in OR with each 10-year rise above 50 years as shown in several previous studies. ${ }^{6,16,19,21,22}$ Though it should be considered if the fixed $\mathrm{FEV}_{1} / \mathrm{FEV}$-ratio enhances this effect due to the general decline in lung function with increasing age. A study by Roberts et al suggests using lower limits of normalityin COPD diagnostics as the age-dependent 
decrease in $\mathrm{FEV}_{1} / \mathrm{FVC}$-ratio tends to cause overdiagnosis of COPD with increasing age. ${ }^{23}$

A strong association was found between COPD and BMI $<25 \mathrm{~kg} / \mathrm{m}^{2}$. These findings are consistent with those presented by Minas et al and Price et al. Interestingly, we found an association between obesity (BMI $>35 \mathrm{~kg} / \mathrm{m}^{2}$ ) and COPD, which was not found in the study by Minas et $\mathrm{al}^{16}$ and is directly contrary to the findings by Price et al. ${ }^{22}$ A potential explanation is the sheer size of the dataset (1,185 cases) in our study, compared to Minas et al (281 cases) and Price et al (155 cases), which is likely to allow the signal to come through. Another possible explanation for the differences in findings may be the choice of reference group, as Price et al used BMI $<25 \mathrm{~kg} / \mathrm{m}^{2}$ as the reference group and with this found a higher COPD risk for those with a BMI $>35$, together with our choice of BMI $\geq 25$ to $\leq 35 \mathrm{~kg} / \mathrm{m}^{2}$ as the reference group compared with a higher risk of COPD in those with BMI $<25 \mathrm{~kg} / \mathrm{m}^{2}$. Our findings are in line with findings by Jordan et al ${ }^{18}$ who found BMI $<25 \mathrm{~kg} / \mathrm{m}^{2}$ showed a significantly increased probability of COPD.

\section{Strengths and limitations}

This was a large-scale multicenter study with almost 400 participating GPs and 6,710 screened subjects. All subjects were screened using spirometry followed by a bronchodilator reversibility test for individuals having airflow limitation at screening spirometry, and the diagnostic workup was, therefore, done per GOLD. ${ }^{13}$

All tests were carried out by the GP and his/her staff, and the quality of the spirometry is therefore likely to be lower than those performed in a respiratory outpatient clinic. Furthermore, the GPs own equipment was used for all spirometry tests. It is likely that calibration and quality checkups are performed less regularly as well compared to an outpatient clinic where spirometry tests are done in almost all patients. However, general practice is the place where most patients with possible COPD are initially examined, so the potential bias introduced by the setup in the present study is likely to be very close to the real-life scenario.

\section{Conclusion}

According to the present study, symptomatic smokers and ex-smokers with dyspnea, phlegm and wheeze have a significantly higher risk of being diagnosed with COPD. Furthermore, BMI $<25 \mathrm{~kg} / \mathrm{m}^{2}, \mathrm{BMI}>35 \mathrm{~kg} / \mathrm{m}^{2}$, increasing age and an increasing number of pack-years smoked were important predictors and highlight a group of high-risk patients that GPs should be increasingly aware of and steps should be taken to ensure that these patients are diagnosed in order to pave the way for early intervention.

\section{Acknowledgments}

The preliminary findings of this paper were presented at the annual meeting of the European Respiratory Society, 2018, at a thematic poster session, and the abstract was published in Eur Respir J; 2018;52(suppl 62):PA756.

\section{Disclosure}

CSU has received a fee for being a member of the study steering committee. The authors report no other conflicts of interest in regard to this work.

\section{References}

1. The top 10 causes of death http://www.who.int: WHO; 2017 [updated January 2017]. Available from: http://www.who.int/mediacentre/fact sheets/fs310/en/

2. European Lung White Book www.erswhitebook.org: European Respiratory Society. Available from: https://www.erswhitebook.org/ chapters/the-burden-of-lung-disease/. Accessed August 1, 2018.

3. Lokke A, Ulrik CS, Dahl R, et al. Detection of previously undiagnosed cases of COPD in a high-risk population identified in general practice. COPD. 2012;9(5):458-465. doi:10.3109/15412555.2012.685118

4. Maltais F, Dennis N, Chan CK. Rationale for earlier treatment in COPD: a systematic review of published literature in mild-to-moderate COPD. COPD. 2013;10(1):79-103. doi:10.3109/15412555. 2012.719048

5. Kanner RE, Connett JE, Williams DE, Buist AS. Effects of randomized assignment to a smoking cessation intervention and changes in smoking habits on respiratory symptoms in smokers with early chronic obstructive pulmonary disease: the lung health study. $\mathrm{Am} \mathrm{J}$ Med. 1999;106(4):410-416.

6. Vandevoorde J, Verbanck S, Gijssels L, et al. Early detection of COPD: a case finding study in general practice. Respir Med. 2007;101(3):525-530. doi:10.1016/j.rmed.2006.06.027

7. Kjeldgaard P, Lykkegaard J, Spillemose H, Ulrik CS. Multicenter study of the COPD-6 screening device: feasible for early detection of chronic obstructive pulmonary disease in primary care? Int J Chron Obst Pulm Dis. 2017;12:2323-2331. doi:10.2147/COPD.S136244

8. Tupper OD, Kjeldgaard P, Lokke A, Ulrik CS. Predictors of COPD in symptomatic smokers and ex-smokers seen in primary care. Chron Respir Dis. 2018;15(4):393-399. doi:10.1177/1479972318761655.

9. Madsen FMN, Mortensen J, Pedersen OF. Lungefunktionsstandard (in Danish). Danish Soc Respir Med. 2007. Available from: www. lungemedicin.dk

10. Fletcher CM, Elmes PC, Fairbairn AS, Wood CH. Significance of Respiratory Symptoms and the Diagnosis of Chronic Bronchitis in a Working Population. Br Med J. 1959;2(5147):257-266.

11. Quanjer PH, Tammeling GJ, Cotes JE, et al. Symbols, abbreviations and units. Working Party Standardization of Lung Function Tests, European Community for Steel and Coal. Eur Respir J Suppl. 1993;16:85-100. doi:10.1183/09041950.085s 1693

12. Medical Research Council. Medical Research Council Dyspnoea scale. Available from: https://mrc.ukri.org/research/facilities-andresources-for-researchers/mrc-scales/mrc-dyspnoea-scale-mrc-breath lessness-scale/. Accessed August 1, 2018.

13. Global Strategy for the Diagnosis, Management, and Prevention of Chronic Obstructive Pulmonary Disease 2018 Report. Global Initiative for Chronic Obstructive Lung Disease 2018. Available from: https://goldcopd.org. Accessed August 1, 2018. 
14. Miravitlles M, Soriano JB, Garcia-Rio F, et al. Prevalence of COPD in Spain: impact of undiagnosed COPD on quality of life and daily life activities. Thorax. 2009;64(10):863-868. doi:10.1136/ thx.2009.115725

15. Hansen JG, Pedersen L, Overvad K, Omland O, Jensen HK, Sorensen HT. The Prevalence of chronic obstructive pulmonary disease among Danes aged 45-84 years: population-based study. COPD. 2008;5 (6):347-352. doi:10.1080/15412550802522635

16. Minas M, Hatzoglou C, Karetsi E, et al. COPD prevalence and the differences between newly and previously diagnosed COPD patients in a spirometry program. Primary Care Respir J. 2010;19(4):363370. doi:10.4104/pcrj.2010.00034

17. Llordes M, Jaen A, Almagro P, et al. Prevalence, risk factors and diagnostic accuracy of COPD among smokers in primary care. COPD. 2015;12(4):404-412. doi:10.3109/15412555.2014.974736

18. Jordan RE, Adab P, Sitch A, et al. Targeted case finding for chronic obstructive pulmonary disease versus routine practice in primary care (TargetCOPD): a cluster-randomised controlled trial. Lancet Respir Med. 2016;4(9):720-730. doi:10.1016/S2213-2600(16)30149-7
19. Ohar JA, Sadeghnejad A, Meyers DA, Donohue JF, Bleecker ER. Do symptoms predict COPD in smokers? Chest. 2010;137(6):13451353. doi:10.1378/chest.09-2681

20. Medbo A, Melbye $H$. What role may symptoms play in the diagnosis of airflow limitation? A study in an elderly population. Scand J Prim Health Care. 2008;26(2):92-98. doi:10.1080/ 02813430802028938

21. Freeman D, Nordyke RJ, Isonaka S, et al. Questions for COPD diagnostic screening in a primary care setting. Respir Med. 2005;99 (10):1311-1318. doi:10.1016/j.rmed.2005.02.037

22. Price DB, Tinkelman DG, Nordyke RJ, Isonaka S, Halbert RJ, Group CQS. Scoring system and clinical application of COPD diagnostic questionnaires. Chest. 2006;129(6):1531-1539. doi:10.1378/chest. 129.6.1531

23. Roberts SD, Farber MO, Knox KS, et al. FEV1/FVC ratio of $70 \%$ misclassifies patients with obstruction at the extremes of age. Chest. 2006;130(1):200-206. doi:10.1378/chest.130.1.200

\section{Publish your work in this journal}

The International Journal of COPD is an international, peer-reviewed journal of therapeutics and pharmacology focusing on concise rapid reporting of clinical studies and reviews in COPD. Special focus is given to the pathophysiological processes underlying the disease, intervention programs, patient focused education, and self management protocols. This journal is indexed on PubMed Central, MedLine and CAS. The manuscript management system is completely online and includes a very quick and fair peer-review system, which is all easy to use. Visit http://www.dovepress.com/testimonials.php to read real quotes from published authors. 